\title{
The role of life orientation and Islamic lifestyle in predicting of life quality \\ in elderly people
}

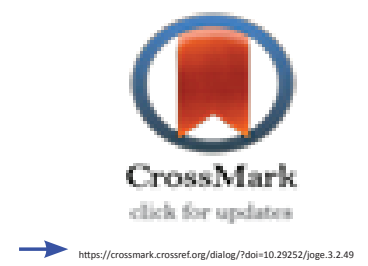

*Atadokht $\mathrm{A}^{1}$, Rahimi $\mathrm{S}^{2}$, shafaie $\mathrm{P}^{3}$

1- Associate Professor of psychology, University of Mohaghegh Ardabili. Ardebil, Iran (Corresponding Author)

Email: Ak_atadokht@yahoo.com

2- M.Sc. in public Psychology, University of Mohaghegh Ardabili, Ardabil, Iran.

3- M.Sc. in Clinical Psychology, Islamic Azad University of Ardebil, Ardebil, Iran.

\section{Abstract}

Introduction: Today, quality of life is one of the biggest health goals in health care and is an effective factor in the life of the elderly. So The purpose of this study was to investigate the role of life orientation and Islamic life-style in order to predicting the quality of elderly people life.

Method: The method of this descriptive-correlational study was the statistical population of all elderly people in Bileh-e-savar city in Ardebil province in the first half of 2018. A sample of 100 people were selected through available sampling method. Then they responded to the questionnaire of Islamic lifestyle, life orientation and quality of life (SF-36). Data were analyzed using Pearson correlation and multiple regression tests.

Results: The results showed that there is a positive relationship between Islamic lifestyle and optimistic life orientation with the quality of life of the elderly, but there is a negative relationship between the pessimistic life orientation and their quality of life $(\mathrm{P}>0.01)$. Regression analysis showed that $45 \%$ of the total variance in the quality of life was specified by the component of Islamic lifestyle and life orientation.

Conclusion: This study has been Solutions for pathologists, especially elderly medicine, to promote lifestyle Islamic life-style, mental health and quality of life for the elderly.

Keywords: life orientation, Islamic lifestyle, life quality, elderly.

\begin{tabular}{|l|l|}
\hline \multicolumn{3}{|c|}{ Access this article online } \\
\hline
\end{tabular}




\section{نقش جهت تيرى زندَى و سبك زندىى اسلامى در بيشبينى كيفيت زندكى سالمندان

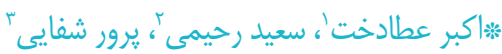

إ- دانشيار كروه روانشناسى، دانشكده علوم تربيتى و روانشناسى، دانشكاه محقق اردبيلى، اردبيل، ايران (نويسنده مسئول) يست الكترونيكى: Ak_atadokht@yahoo.com r- كارشناس ارشد روانشناسى عمومى، دانشخاه محقق اردبيلى، اردبيل، ايران.

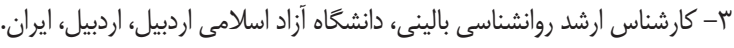

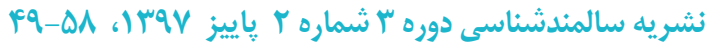

\section{مقدمه: امروزه، كيفيت زندَّى يكى از بزر كَترين اهداف بهداشتى در مراقبت سلامتى محسوب شده و و عاملى مؤثر در زندَّى سالمندان}

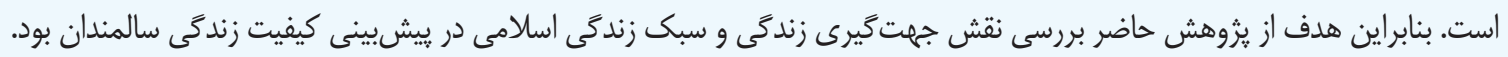

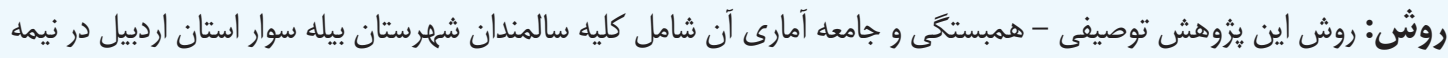

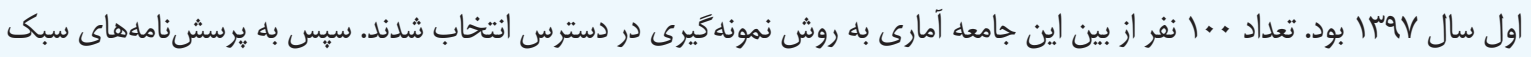

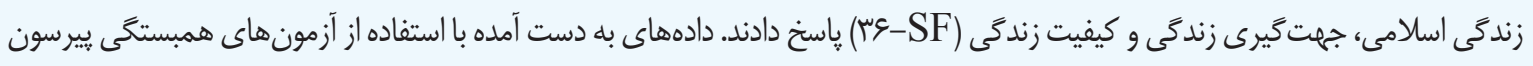

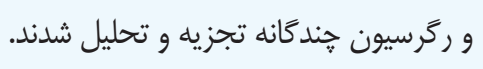

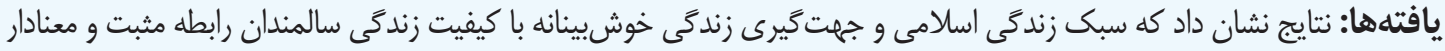

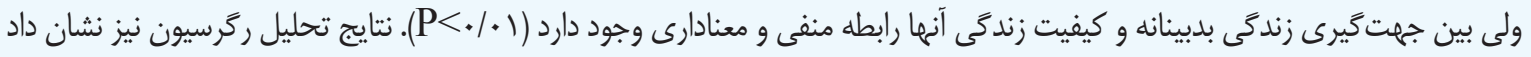

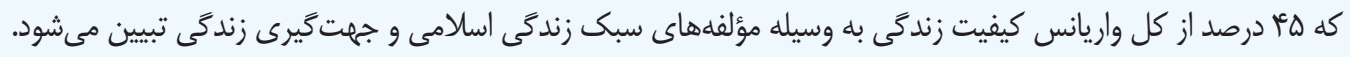

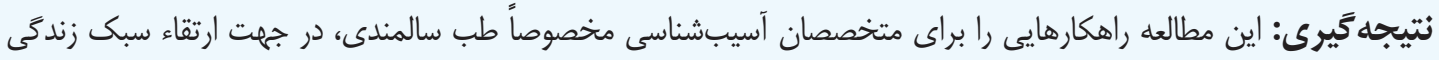

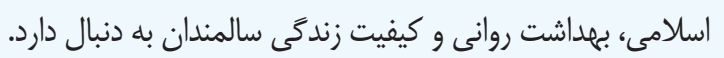

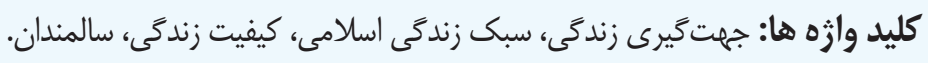


آميزترين علت هر شكست و داشتن انتظارات منفى براى نتايج

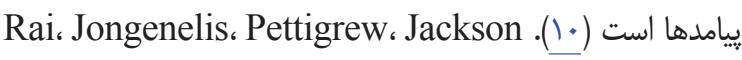
و Newton (1) به اين نتيجه دست يافتند كه افسردگى به صورت (1) بالت منفى و خودكارآمدى به صورت مثبت و غيرمستقيم با خوشيبنى سالمندان از طريق بجزيستى روان شناختى و كيفيت زندگى مرتبط است. Giaquinto و Gison، Rizza، Bonassi، Donati (IT) طى يزوهشى دريافتند كه خوشيينى و جهت خوشبينانه با ارتقاى كيفيت زندگى ارتباط مثبت معنادارى دارد. Shifren و Colby سلامت روان و كيفيت زندگى را تبيين نمايد. از عوامل ديگرى كه مى تواند در كيفيت زندگى سالمندان مؤثر

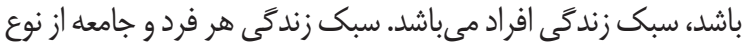

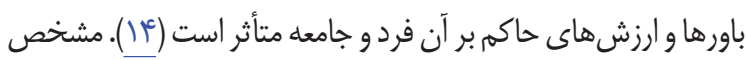
است كه جهان بينى مادى به طور طبيعى سبك زندگى خاصى را

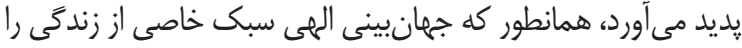
شكل مىدهد (ه)). امروزه بسيارى از صاحبنظران و يزوهشخَران به مفهوم سبك زندگى اسلامى (islamic lifestyle) توجه

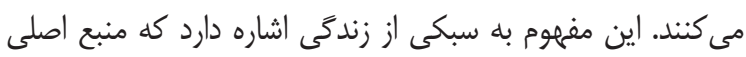

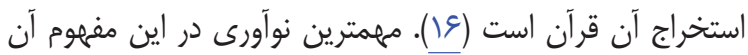

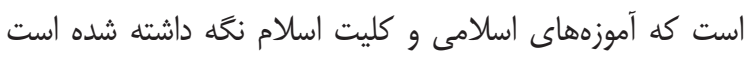

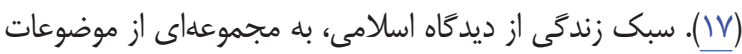
مورد قبول اسلام در عرصهى زندگى اشاره دارد كه بر اساس آن، معيار رفتار ما بايد مبتنى بر اسلام و آموزههاى اسلامى باشد. خدا محورى

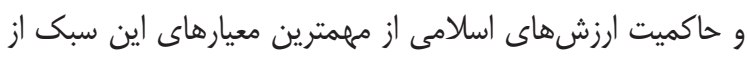

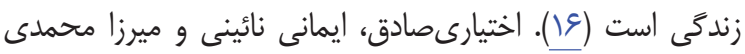

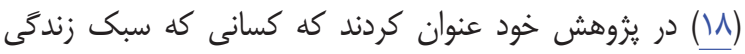
اسلامى بالاترى دارند از شاخصهاى سلامت بهترى برخوردارند.

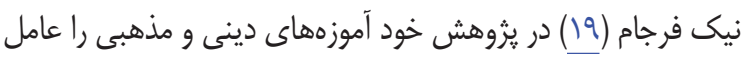

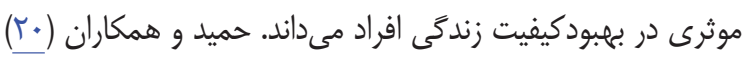
نيز درمانهاى مذهبى را راهكارى براى افزايش اميد به زندگى و

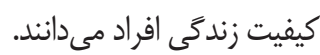
در نهايت اينكه با توجه به افزايش روزافزون جمعيت افراد سالمند و نيز بادر نظر كَرفتن بافت فرهنكى كشور، روابط مستحكم

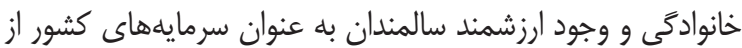
يك سو، و كم بودن حجم يثوهش وهاى انجام كَرفته در اين زمينه و از از

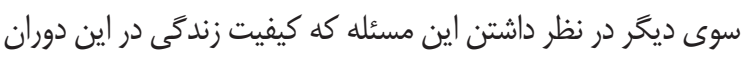

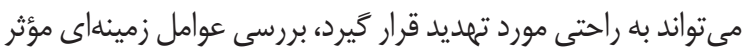
بر كيفيت زندگى سالمندان از اهميت بالقوهاى برخوردار است. بنابراين

\section{مقاله}

سالمندى (elderly) مرحلهاى از تكامل زندگى بشر بوده و فر آيندى طبيعى، بيولوزيكى و جهانى است. امروزه، يكى از بز ركترين

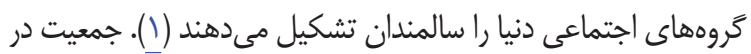
سراسر جهان به سرعت در حال يير شدن است، در نتيجه افزايش

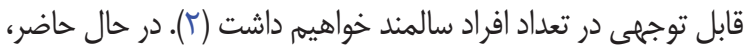
جمعيت بالاى •و سال جهان حدود با درصد مى داشد و اين نسبت

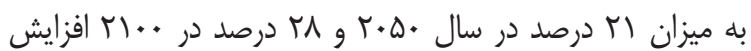
خواهد يافت (ّ). در ايران نيز بر اساس اطلاعات سرشمارى عمومى درى

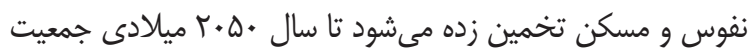
سالمندان ايران به بيش از عَ ميليون نفر برسد، كه در آن آن سالمندان ع درصد از كل جمعيت كشور را تشكيل خواهند داد (ع). يكى از مسايل عمده جمعيتى، ييامدهاى ناشى از سالمندى است. در واقع سالمندى تركيبى از تغييرت زيستشناختى،

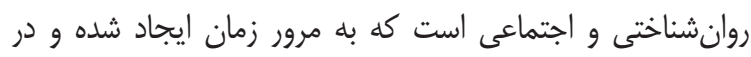
نهايت باعث افزايش احتمال مرك و مير مى شود (ه). با بروز دوران سالمندى، افراد دشوارى در انجام مستقل امور روزانه را تجربه كرده و

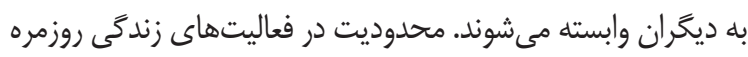

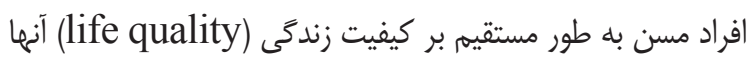
تأثير مى كذارد (9). امروزه، كيفيت زندكّى يكى از مهمترين مسايل عمر و يكى از بزر كتر ين اهداف بهداشتى در مراقبت سلامتى محسوب

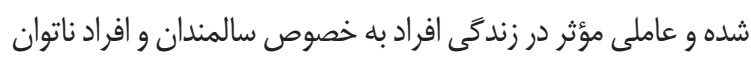

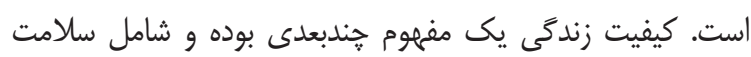
بدنى، سلامت روانى، شرايط اقتصادى، تعامل با محيط، باورهاى

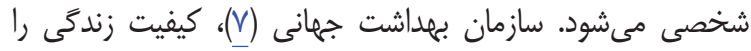

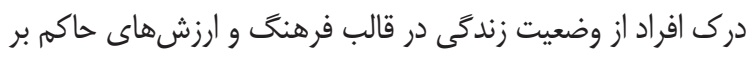
جامعه و در راستاى اهداف، استانداردها و علايق افراد تعريف نموده فرداي

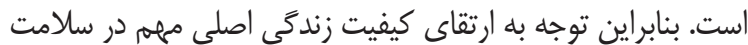
و بهداشت جامعه مى باشد (^). يكى از عواملى كه مىتواند در كيفيت زندگى سالمندان نقش داشته باشد، جهت گيرى زندگى (life orientation) است. جهت گيرى زندگى اشاره به ديدگاه و نحَرش كلى فرد نسبت به زندَّى و رويدادهايى است كه براى او اتفاق مى افتد يا در آينده اتفاق خواهد افتاد و جهت كيرى زندگَى در واقع منعكس كننده تفاوتهاى

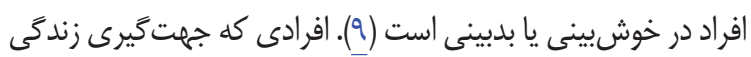
خوشيينانه دارند، انتظار دارند رويدادهاى خوب و مثبتى براى آنها به وجود آيد، در حالى كه جهت كَيرى زندگى بديينانه تاكيد بر فاجعه 
(Life Orientation examination (LOT-R) آزمون توسط Scheier، Carver و Bridges (9) براى افراد سنين نوجوانى و بالاتر تدوين شد و ميزان خوشيبنى سرشتى افراد را با •ا عبارت و در طيف ه درجهاى از كاملاً موافقم (ه) تا كاملاً

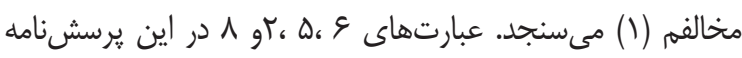

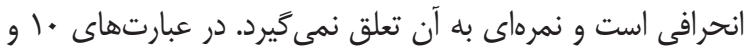

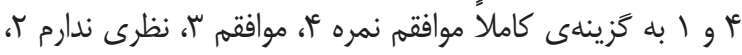

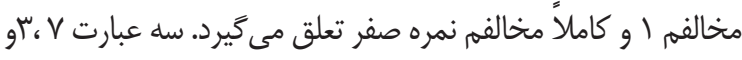

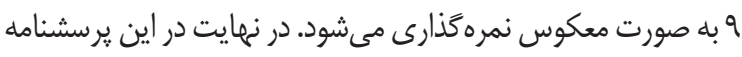
ياسخخكويان، نمرهاى مابين صفر تا بيست و جهار كسب مى كنند.

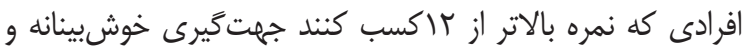

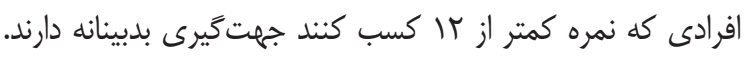
روايى همزمان اين مقياس در جندين يثوهش با مقياسهاى ديخر

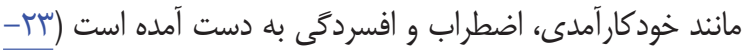

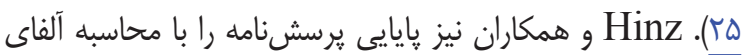

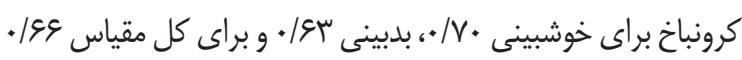

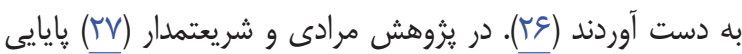

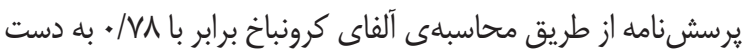

".ا. يرسشنامه سبك زندَّى اسلامى: اين يرسشنامه كه توسط

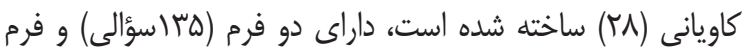
كوتاه (צVؤوالى) مىباشد كه در اين يثوهش، از فرم كوتاه آن استفاده شده است. اين آزمون شامل ده مؤلفه: ا- مؤلفه اجتماعى r- م- مؤلفه

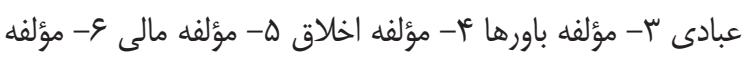
خانواده V- مؤلفه سلامت ^- مؤلفه تفكر و علم q- مؤلفه دفاعى - مؤل

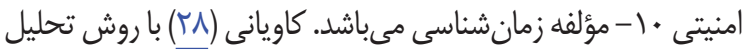

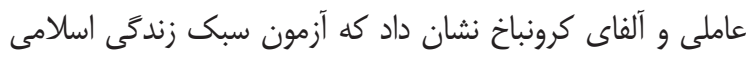

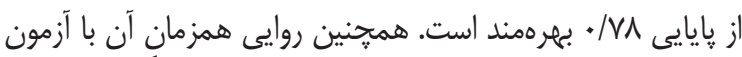

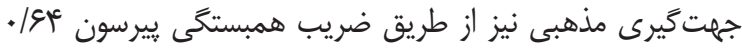

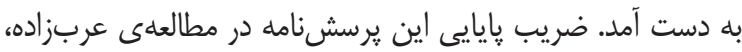

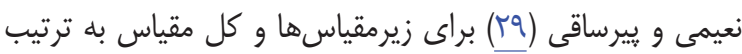

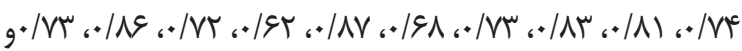

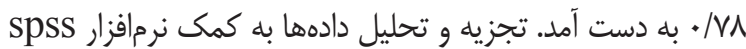

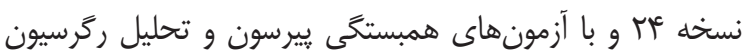

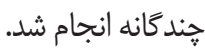

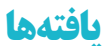

نمونه يزوهش كه شامل ..1 نفر از سالمندان شهرستان

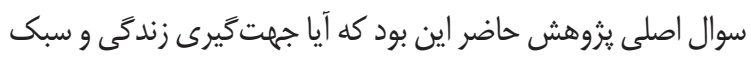
زندگى اسلامى مىتوانند كيفيت زندَّى سالمندان را ييشيبنى كنند؟

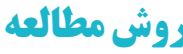

روش يثوهش با توجه به ماهيت موضوع توصيفى از نوع همبستگى بود و جامعه آمارى مورد مطالعه، شامل كليه سالمندان ساكن در شهرستان بيلهسوار استان اردبيل در نيمه اول سال Vوسار بودند. با توجه به اينكه در تحقيقات توصيفى حداقل حجم نمونه ـ.

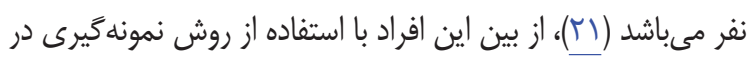
دسترس و با رعايت ملاكهاى ورود از قبيل داشتن سواد خواندن و نوشتن و سن بالاى •و سال، تعداد ..1 نفر بعد از مراجعه يزوهشكر

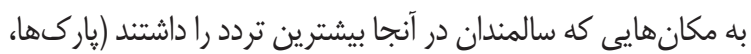
مساجد و...)، به عنوان نمونه انتخاب شدند. جهت تكميل يرسشنامهها

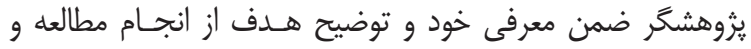

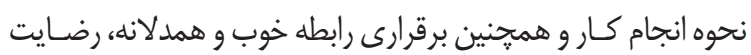

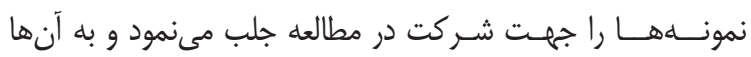
اطمينان خاطر داده مىشد كه اين آزمونها و نتايج به دست آمده از

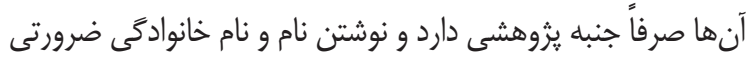

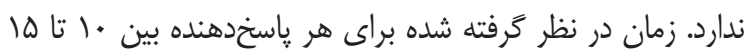

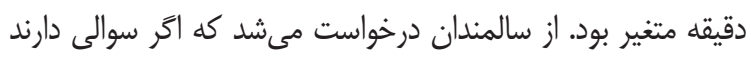

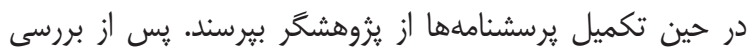

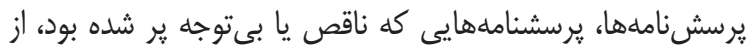

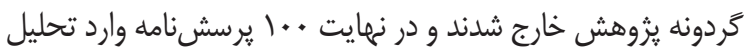
شدند. براى جمع آورى اطلاعات از ابزارهاى زير استفاده كَرديد: ا. مقياس كيفيت زندَّى عب سوالى (Short- form) -questions) (SF $\mathrm{S}$ health assessment with

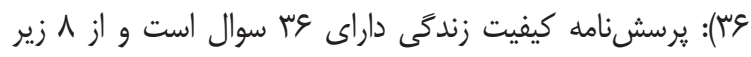

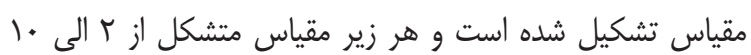
ماده است. هشت زير مقياس اين يرسشنامه عبارتند از : عملكرد

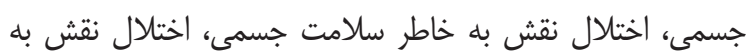

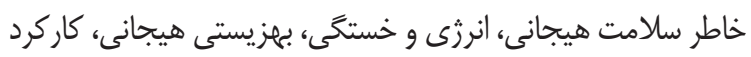

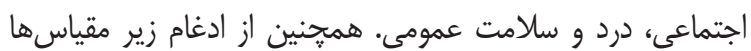

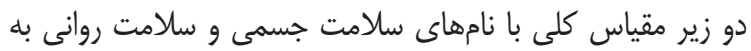

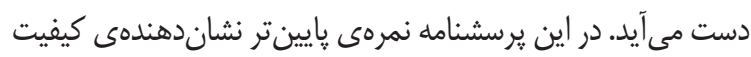

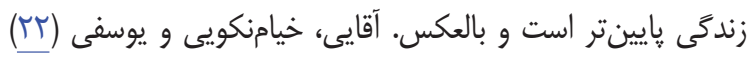

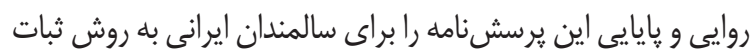

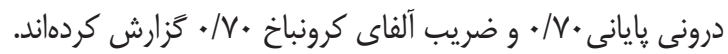

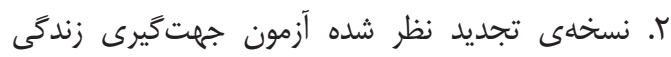


ليسانس كمترين فراوانى را با حدود أ درصد (أl n) نمونه داشتند.

براى بررسى نرمال بودن توزيع فراوانى دادهها از آزمون كولموكروف لمدين

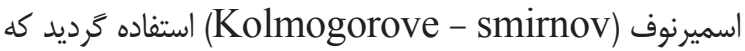
نتايج آن نشان داد كه دادهها داراى توزيع نرمال بودند..

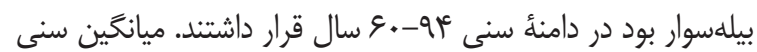

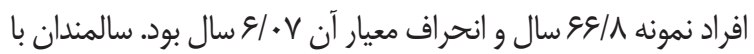

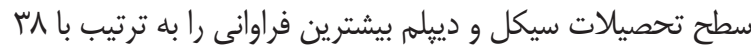

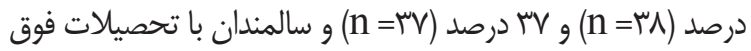

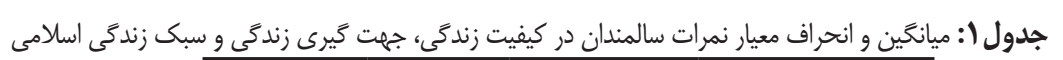

\begin{tabular}{|c|c|c|c|}
\hline انحراف معيار & ميانخين & آيتمها & متغير \\
\hline$r / \Lambda)$ & $1 \Delta / \Gamma \Delta$ & جسمانى & \multirow{5}{*}{ كيفيت زندگى } \\
\hline T/T & $|r / \Lambda|$ & روانشناختى & \\
\hline 1/DT & $|r / 9|$ & روابط اجتماعى & \\
\hline r/^q & $|r / v|$ & سلامت محيط & \\
\hline $1 . / \mathrm{Vq}$ & $r N / N$ & نمره كل & \\
\hline$V / T I$ & $0 \cdot / 8 \mathrm{~V}$ & اجتماعى & \multirow{11}{*}{ سبك زندگى اسلامى } \\
\hline$V / M$ & $r q / \wedge$ & عبادى & \\
\hline 1.199 & $98 / .1$ & باورها & \\
\hline$q / \cdot r$ & $\Delta N / 11$ & اخلاق & \\
\hline$N / \cdot 9$ & $9 N / 9$ & مالى & \\
\hline $19 / 1 V$ & $\Delta \Delta / 19$ & خانواده & \\
\hline$r / \cdot \varphi^{c}$ & $19 / 71$ & سلامت & \\
\hline N/T & $01 / .9$ & تفكر و علم & \\
\hline$\Delta / \varepsilon$. & $r \Delta / \& q$ & دفاعى - امنيتى & \\
\hline r/qu & $|c| / 91$ & زمانشناسى & \\
\hline rq/ru & $199 / \wedge f$ & نمره كل & \\
\hline$r / \Delta Q$ & $\mid r / \cdot r$ & خوشبينى & \multirow{2}{*}{ جهت } \\
\hline$\mu / \mu F$ & If/T & بدبينى & \\
\hline
\end{tabular}

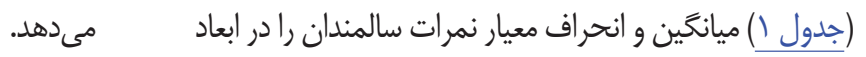

كيفيت زندگى، جهت

\begin{tabular}{|c|c|c|c|c|c|c|}
\hline كيفيت زندگى سالمندان & سلامت محيط & روابط اجتماعى & 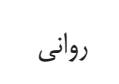 & جسمانى & \multicolumn{2}{|c|}{ متغيرها } \\
\hline$\cdot /\left.F \Delta\right|^{*: s}$ & 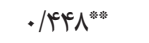 & $\cdot / \Psi Y^{*}$ & 年 & 年 & اجتماعى & \\
\hline •/TGY:" & $\cdot|\mu| f^{* * a n}$ &.$/ M$ & . $/$ THA* & $.|| r \mid$ & عبادى & \\
\hline$\cdot / \mu r^{* * * b}$ & 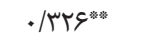 & . & . & $\cdot / T \Delta V^{* w a}$ & باورها & \\
\hline - $/$ sye & 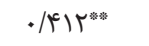 & . & 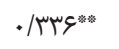 & 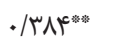 & اخلاق & \\
\hline$\cdot / 499 * \%$ & •/KFq": & . & $\cdot|\Delta F|^{* *}$ & $\cdot / f^{* * n k}$ & مالى & \\
\hline ( & . &.$/ 191$ &.$/ \mu 19^{* * *}$ & $\cdot / T \wedge 9^{* * *}$ & خانواده & سبك زندگى اسلامى \\
\hline$\cdot / T \cdot \Delta^{*}$ & •/Krצ" &.$/ 14 \wedge$ &.$/ 190$ &.$/ 1 V^{2}$ & سلامت & \\
\hline. $\mid \wedge \& D^{* * *}$ & 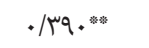 & •/rag:*a: &.$/ 419^{* * *}$ & . & تفكر و علم & \\
\hline . / Fr人": & . $/ 4 r b^{* * a}$ & $\cdot / T V g^{* * a}$ & $\cdot / \uparrow \wedge \cdot * *$ & ./TFq" & امنيتى دفاعى & \\
\hline ( & •/TYQ &.$/ 1 m$ & . /TEY" & ( & زمانشناسى & \\
\hline. $\mid \Delta \Lambda)^{* *}$ & $\cdot / \Delta T V^{m *}$ & $\cdot / \Gamma \Lambda \kappa^{* * *}$ & $\cdot|Q H|^{* * *}$ & $\cdot / \mp \Delta \cdot{ }^{*}$ & سبك زندگى اسلامى & \\
\hline 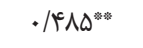 & $\cdot / \Delta Y)^{* * *}$ & 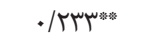 & ( & $\cdot / \pi \checkmark \cdot *$ & خوشبينى & \\
\hline$-\cdot / \Gamma \vee \Delta^{* *: *}$ & 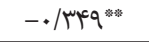 & 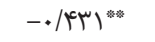 &.$- / 199^{*}$ & $-\cdot / r \Delta \varphi^{* * *}$ & بدبينى & \\
\hline
\end{tabular}

* $\mathrm{P}<\cdot / \cdot \Delta \quad$ * $* \mathrm{P}<\cdot / \cdot 1$

با توجه به نتايج (جدول ب) همبستخى بين كيفيت زندگى و اجتماعى و سلامت محيط) و سبك زندگى اسلامى رابطه مثبت و

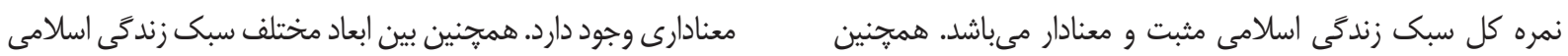

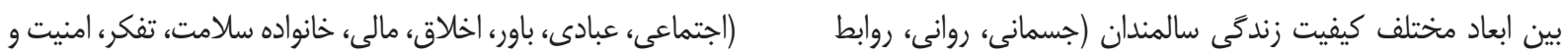


مىباشد. در اين ثروهش قوىترين ارتباط بين كيفيت زندگى و نمره

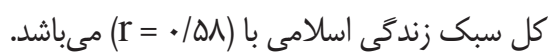

زمانشناسى) با كيفيت زندگى سالمندان رابطه معنى دارى وجود دارد.

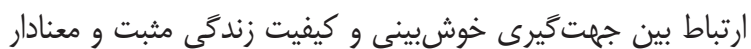
و ارتباط بين جهت گيرى بديينى و كيفيت زندَى منفى و معنادار

\begin{tabular}{|c|c|c|c|c|c|c|c|}
\hline $\mathrm{R}^{r}$ & $\mathrm{R}$ & سطح معنىدارى & $\mathrm{F}$ & ميانكين مجذورات & df & مجموع مجذورات & مدل \\
\hline ه &.$/ 9 \mathrm{~V}$ & $<\cdot 1 \cdot .1$ & $9 / 49$ & $\begin{array}{l}r V V / \Delta q \varepsilon \\
V r / q V T\end{array}$ & $\begin{array}{l}11 \\
11 \\
91\end{array}$ & 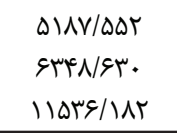 & باقيمانده \\
\hline
\end{tabular}

جهت گيرى زندَّى و سبك زندَّى اسلامى قابل تبيين است.

(جدولب) نشان مىدهد كه مدل كلى معنىدار است

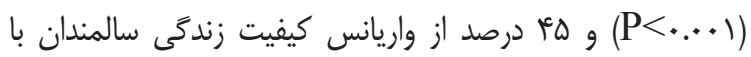

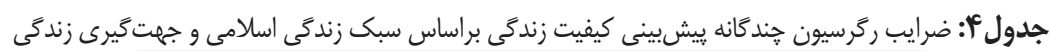

\begin{tabular}{|c|c|c|c|c|}
\hline Sig & $\mathrm{T}$ & ضريب ركَرسيون & $\beta$ & متغيرها \\
\hline$\cdot 1 \cdots 0$ & $1 / \Delta A C$ & - & $\mid Q / .9$ & مقدار ثابت \\
\hline ./.re & I/DTE &.$/ 14$ & - /TAS & اجتماعى \\
\hline $.1 \cdot p^{a t}$ & IVIV &.$/ 114$ & $\cdot / r \mid \Lambda$ & عبادى \\
\hline$\cdot 1 \cdot 1$ & . IST &.$/ .1 \mathrm{~V}$ &.$/ 19 V$ & باورها \\
\hline . & 1/FET & $\cdot / / Q \Lambda$ &.$/ 111$ & اخلاق \\
\hline .1 .94 & ו וא/ו & $. / 1 \times 9$ &.$/ 199$ & مالى \\
\hline$\cdot / 1 \mathrm{Vr}$ & $.199 \mathrm{~V}$ & $\cdot 1 \cdot v 1$ &.$/ \cdot \Lambda \Delta$ & خانواده \\
\hline.$/ .1 \mathrm{~V}$ & ./TAV &.$/ \cdot Y \Lambda$ &.$/ 1$ & سلامت \\
\hline$. / 1 F \mid$ & $\cdot / \mu \wedge$ & $.1+4$. &.$/ . \Delta T$ & تفكر و علم \\
\hline$\cdot / \cdot v$ & $r / V E \Delta$ & . /TAV & $\cdot / \Delta \Delta \Lambda$ & امنيتى - دفاعى \\
\hline.$/ .14$ & T/TAT & . & . & زمانشناسى \\
\hline $.1 \cdot T F$ & I/ITK & .1 .94 & . MNAr & خوشبينى \\
\hline سז./. & זسM/.-- &.$- / 1 T V$ & -. & بدبينى \\
\hline
\end{tabular}

بين مؤلفه بدبينى جهت گيرى زندَّى با ابعاد مختلف كيفيت زندَى سالمندان رابطه منفى وجود دارد، همجنين مؤلفهاى جهت زندگى مىتوانند كيفيت زندگى سالمندان را تبيين كنند. اين نتايج

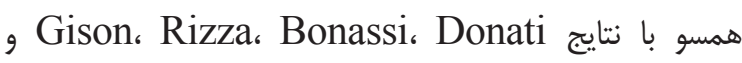
Shifren g Colby و (I) Giaquinto تبيين اين يافته مىتوان بيان نمود كه طبق يُوهشهاى صورت كرفته خوشبينها رفتارهاى مقابلهاى مؤثرتر، روابط اجتماعى بالاتر و بهتر، انعطافيذيرى بالاتر و بهزيستى ذهنى و جسمى بيشترى

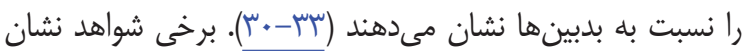
مىدهد، سطوح بالاى خوشيينى در سالمندان با سلامت روان

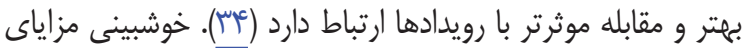
متعددى دارد. اين صفت كمك مى كند تا فرد در برابر افسردگى و بيمارى كه منجر به شكست و وقايع ناكوار زندگى مى شود، ايستادگى كند. اين موهبت به فرد كمك مى كند تا در مقايسه با آنهه كه ديخران از او انتظار دارند موفقيت بيشترى در زندگى و اجتماع به

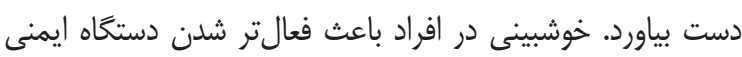
مى گردد كه اين امر موجب كمتر شدن بيمارى و مراجعل كمتر به
جهت گيرى زندگى (خوشيينى، بدبينى) و ابعاد سبك زندگى

اسلامى (اجتماعى، عبادى، باورها، اخلاق، مالى، خانواده، سلامت،

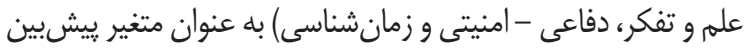
و كيفيت زندگى به عنوان متغير ملاك درمعادله ركرسيون تحليل

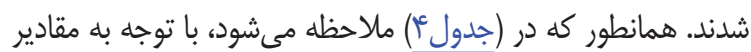
بتاى خوشبينى، بدبينى، زمانشناسى، دفاعى - امنيتى، سلامت،

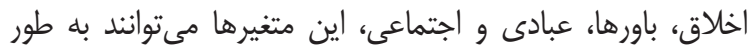

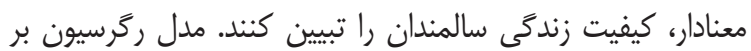
اساس ابعاد سبك زندگى اسلامى علم و تفكر، خانواده و مالى معنادار نمىباشد و اين متغيرها نمىتوانند تغييرات مربوط به كيفيت زندكى الثى سالمندان را به طور معنادارى بيشيبينى كنند.

يزوهش حاضر با هدف بررسى نقش جهت گيرى زندگى و سبك زندگى اسلامى در ييشبينى كيفيت زندَّى سالمندان انجام קذيرفت. نتايج يزوهش نشان داد كه بين مؤلفه خوشبينى جهت گيرى زندَّى با ابعاد كيفيت زندگى سالمندان رابطه مثبت و 
سالمندى به استقلال و اختيار و همجنين عوامل فردى درونى شامل ميزان ارتباط سالمند با منابع مذهبى و معنوى كه ابعاد سلامت روانى

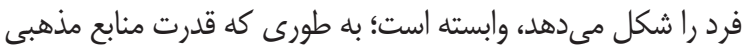

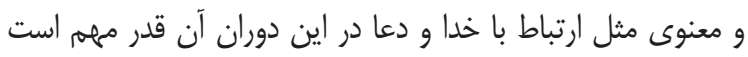
كه مىتواند نقصان و محروميت حمايت خانوادگى و اجتماعى سالمند

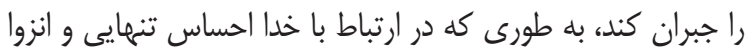
نداشته باشد و به ساز كارى وى كمك كند و كيفيت زندگى فرد را

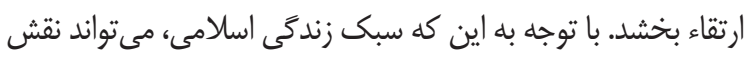

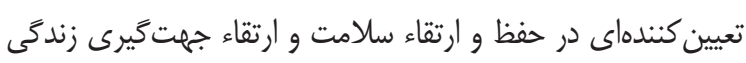

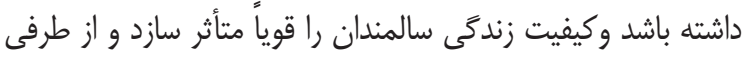
سلامتى، يكى از اجزاء كيفيت زندگى مى باشد و كيفيت زندكى مفهوم

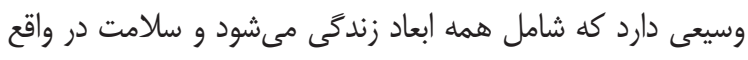

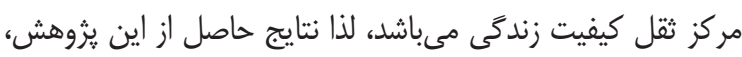
جندان دور از انتظار نيست. از طرفى به نظر مىرسد افرادى كه سبك زندىى اسلامىترى دارند، حمايتهاى اجتماعى و خانوادگى إنى

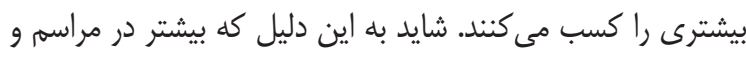
اماكن مذهبى و برخورد با افراد سالم جامعل قرار دارند و همين عامل باعث مىشود كه نكرش شهاى أنها مثبتتر و كار آمدتر باشد. در نتيجه

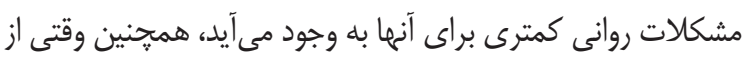
طرف ديكران حمايت مىشويم خود را فردى مطلوب، مفيد، دوست إنى داشتنى و ارزشمند مى دانيم و اين يعنى اين كه نكَرشهائ ما مانسبت

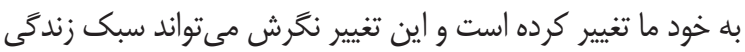
سالمندان را تحت تأثير قرار دهد.

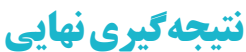

در مجموع نتايج اين مطالعه حاكى از وجود ارتباط ميان سبى

زندگى اسلامى و جهت گيرى زندگى با كيفيت زندگى سالمندان

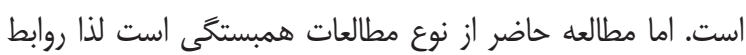

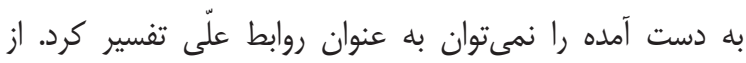

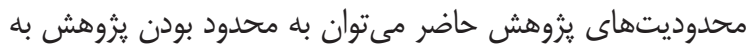

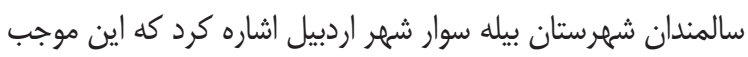
محدوديت در تعميم نتايج مىشود. براى افزايش تعميميذيرى نتايج به يزوهشهاى بيشترى در شهرهاى مختلف نياز هست. يكى از

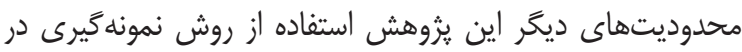
دسترس مىباشد كه تعميم يافتهها بايد با احتياط صورت گيرد. يبشنهاد مىشود در يزوهشهاى ديخر از روشهاى نمونهَيرى تصادفى استفاده شود. در يزوهش حاضر از برسشنامه استفاده شده

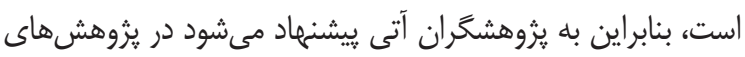

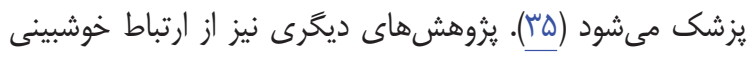

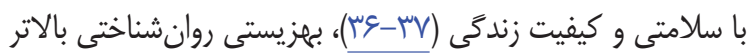

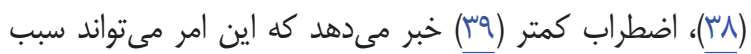
بهبود كيفيت زندگى سالمندان شود. از سوى ديخر يكى از خصوصيات شخصيتى كه مىتواند در

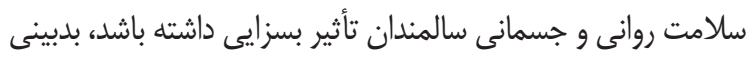
است كه نوعى نحوهُ نخرش فرد نسبت به جهان و رويدادهاست، كهان

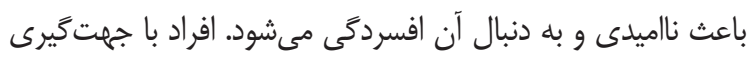

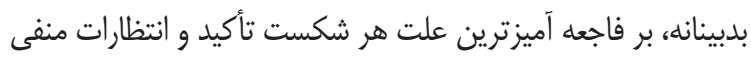
براى نتايج يبامدها دارند (•) أ) اين افراد مردد و نايايدار بوده و انتظار بدبختى دارند (ال)). در واقع بدبينى مشخصه كليدى اضطراب و

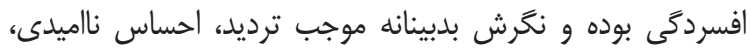

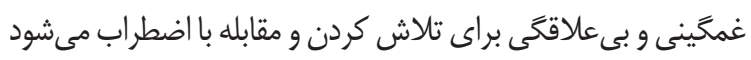
كه اين امر بر كيفيت زندگى سالمندان تأثير منفى مى كذارد.

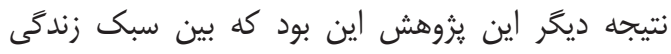
اسلامى با كيفيت زندكى سالمندان رابطه معنى دارى وجود دارد. اين نتايج همسو با نتايج نيك فرجام (19)، حميد و همكاران (•r)

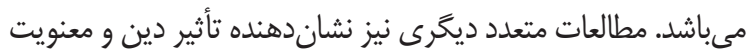

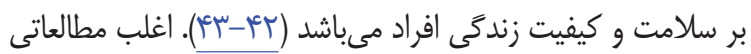
كه در رابطه با مذهب و مقابله با موقعيتهاى يرتنش انجام شدهاند، به نقش مذهب به عنوان شيوهاى براى مقابله با استرس تحت عنوان

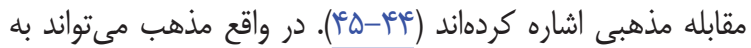
عنوان يك اصل وحدت بخش و يك نيروى عظيم براى ساز كارى

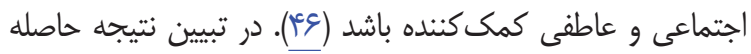
مىتوان بيان نمود كه سالمندى داراى شرايط خاصى است. دورانى

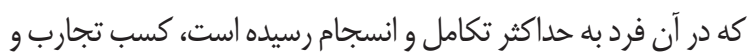
تغييرات جسمى در فرد سبب مىشود ديدكاه سالمند به دنيا ديدًاهى

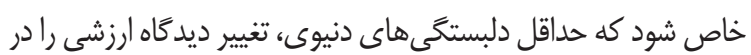

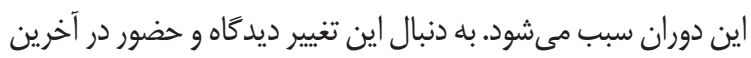
مر حله زندكى توجه به دين و مذهب، اعتقادات سالمند به دنبال آخرت

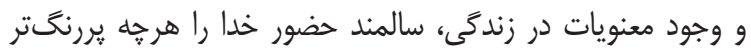
در زندگى احساس مى كند و اين مسئله مهمترين عامل ساز كارى با شرايط اين دوران محسوب مىشود، به طورى كه در بسيارى از مواقع سالمند از داشتن حمايتهاى خانوادگى و اجتماعى محروم

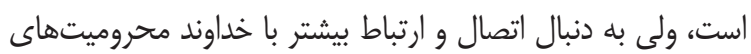
اجتماعى را جبران، و كيفيت زندگى مناسبى كزارش مىكند و از

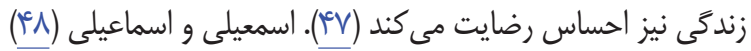
در يزوهش خود به اين نتيجه دست يافتند كه سلامت جسمى در 


$$
\begin{aligned}
& \text { اكبر عطادخت و همكاران - - ان } \\
& \text { سازى افراد از تأثير جهتگيرى زندگى بر كيفيت زندگى سالمندان } \\
& \text { توسط سياست گذاران كلان كشورى صورت گيرد. }
\end{aligned}
$$

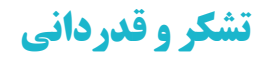

$$
\begin{aligned}
& \text { از تمامى عوامل دست اندركاران انجام اين يزوهش به }
\end{aligned}
$$

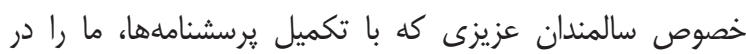

$$
\begin{aligned}
& \text { انجام اين يزوهش يارى نمودند، سياسگَزاريه. اين مقاله مستخرج از }
\end{aligned}
$$

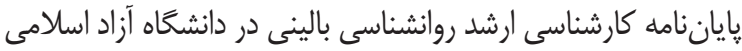

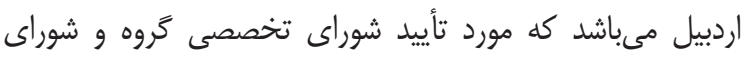

$$
\begin{aligned}
& \text { يثرهشى دانشگاه قرار گرفته است. }
\end{aligned}
$$

\section{References}

1. Sulmasy DP. The varieties of human dignity: a logical and conceptual analysis. Springer; 2013.

2. World Health Organisation. (2015). World report on ageing and health. Retrieved from http:// www.who.int/ageing/events/worldreport - 2015launch/en/.

3. United Nations, Department of Economic and Social Affairs, Population Division. (2017). World population prospects: The 2017 revision, key findings and advance tables. Retrieved from https://esa.un.org/unpd/wpp/ Publications/Files/ WPP2017_KeyFindings.pdf.

4. Mortazavi s ,Eshaghi, Eftekhar Ardebili, H. eshaghe sr, Dorali R, Shahsiah M, Botlani S. The effectiveness of regular activity physical of mental health in elderly. Journal of Isfahan medical school. 2012 1519-1526: (161) 29؛. (Persian)

5. Pakpour V, Zamanzadeh V, Salimi S, Farsiv A, Moghbeli G, Soheili A. The relationship between loneness and sleep quality in older adults in Tabriz. Journal of Urmia Nursing And Midwifery Faculty. 2017; 14 (11): 906-17. (Persian)

6. Tel H, Tel H, Sabanciogulları S. Status of maintenance of activities of daily living and experience of loneliness infielder than 60 years old living at home and in institutions. Türk Geriatri Derg. 2006;9:34-40.

7. World Health Organization. World Health Organization Quality of Life-BREF (WHOQOLBREF).http://www.who.int/substance_abuse research tools/ whoqolbref/en/ Accessed 14 September, 2014.
خود از ابزارهاى ديخً از جمله مصاحبه استفاده كنند. سبك زندگى به

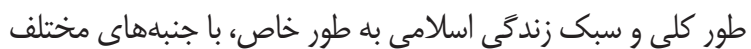
روانى، اجتماعى و جسمانى زندگى افراد ارتباط دارد و متخصصانى كه به نحوى با مسايل درمانى و همجنين يِيشگيرى در ارتباط

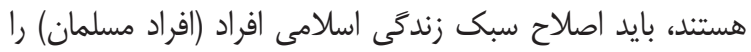
نيز جزء مداخلههاى خود قرار دهند. با توجه به نتايج اين يزوهش و يروهشهاى ديخًر مىتوان نتيجه گَرفت كه به منظور ترويج سلامت جسمى و روانى افراد، بايد اقداماتى را در جهت گرايش سالمندان

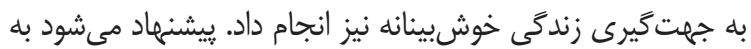
منظور ارتقاء كيفيت زندگى سالمندان، اقداماتى نظير، تهيه و توزيع بروشورهاى آموزشى، برگزارى همايشها و كاركاهها جهت آكاه

8. Burke E, McCarron M, Carroll R, McGlinchey E, McCallion P. What it's like to grow older: the aging perceptions of people with an intellectual disability in Ireland. Mental Retardation. 2014; 52 (3): 205-19.

9. Scheier MF, Carver CS, Bridges MW. Distinguishing optimism from neuroticism (and trait anxiety, self-mastery, and self-esteem): a reevaluation of the Life Orientation Test. Journal of personality and social psychology. 1994; 67 (6): 1063.

10. Galatzer-Levy IR, Bonanno GA. Optimism and death: Predicting the course and consequences of depression trajectories in response to heart attack. Psychological Science. 2014; 25 (12): 2177-88.

11. Rai R, Jongenelis M, Pettigrew S, Jackson B, Newton RU. Identifying modifiable factors associated with health optimism in older adults. Aging \& Mental Health. 2017:1-9.

12. Gison A, Rizza F, Bonassi S, Donati V, Giaquinto S. Effects of dispositional optimism on quality of life, emotional distress and disability in Parkinson's disease outpatients under rehabilitation. Functional neurology. 2015; 30 (2): 105 .

13. Colby DA, Shifren K. Optimism, mental health, and quality of life: a study among breast cancer patients. Psychology, health \& medicine. 2013; 18 (1):10-20.

14. Aksoy N. Weight gain after kidney transplant. Exp Clin Transplant. 2016; 14 (Suppl 3): 138-40.

15. Hamdieh M \& Shahidi S. Principles of Mental Health. 5th ed. Tehran: Publication Samt. 2014. 
pp; 113-29. (Persian).

16. Heirat A, Fatehizadeh SA, Ahmadi D, Bahrami F, Etemadi O. The effect of islamic life style training on marital adjustment. International Journal of Psychology and Behavioral Research. 2015; 4 (3): 268-72. (Persian).

17. Iftikhar R, Albar M, Qadi M. Obesity and life style recommendations in the light of islam. J Fam Med Dis Prev. 2016; 2 (3): 2469-573.

18. Ekhtiary Sadegh M, Imani Naeini M, MirzaMohammadi M H. The Prediction of Loneliness among the Kermanshahi Elderly Based on SelfCompassion, Spirituality, and Islamic Lifestyle. J Res Relig Health. 2018; 4 (2): 69- 80. (Persian).

19. Nikfarjam M. The efficacy of religious training (prayer) on the improvement of the schizophrenic patients' quality of life at Sina Psychiatric Hospital (Bakhtiari Province, 2011). Arak Medical University Journal. 2011; 3 (5). (Persian).

20. Hamid N, Ahmadian A, Akbari Shaye Y. Effectiveness of cognitive behavior therapy based on religious believes on hope and quality of life in the patients suffering breast cancer. Bimonthly Journal of Hormozgan University of Medical Sciences. 2012; 16 (3): 213-21. (Persian).

21. Delaware A. Theoretical and practical research in the humanities and social sciences. tehran Journal roshd. 2007. (Persian).

22. Aghaei A, Khayyamnekouei Z, yousefy AR. General Helth prediction Based on life orientation, Quality of life, life satisfaction and Age. Social and Behavioral sciences. 2013; 84. 569-573. (Persian).

23. Zenger, M., Finck, C., Zanon, C., Jimenez, W., Singer, S., \& Hinz, A. Evaluation of the Latin American version of the Life Orientation TestRevised. International Journal of Clinical and Health Psychology, 2013; 13, 243---252. http:// dx.doi.org/10.1016/S1697-2600 (13)70029-2 .

24. Monzani, D., Steca, P., \& Greco, A. Brief report: Assessing dispositional optimism in adolescence---factor structure and concurrent validity of the Life Orientation Test----Revised. Journal of Adolescence, 2014; 37, 97---101. http://dx.doi. org/ 10.1016/j.adolescence. 2013.11.006.

25. Glaesmer, H., Rief, W., Martin, A., Mewes, R., Brähler, E., Zenger, M., \& Hinz, A. Psychometric properties and population-based norms of the Life Orientation Test Revised (LOT-R). British Journal of Health Psychology, 2012; 17, 432---445. http://dx.doi.org/10.1111/j.20448287.2011.02046.x.

26. Hinz, A., Sander, C., Glaesmer, H., Brähler, E., Zenger, M., Hilbert, A., \& Kocalevent, R.D. Optimism and pessimism in the general population: Psychometric properties of the Life Orientation Test (LOT-R). International Journal of Clinical and Health Psychology, 2017; 17(2), 161-170.

27. Moradi, a, And Shariatmadare, a. (2016). Comparison of Death Anxiety and Loneliness in Elderly with Optimistic and Pessimistic Orientation. Psychology of Aging. 2 (2) .133141. (Persian)

28. Kaviani, M (2009). Compilation and evaluation of Islamic lifestyle, Ravanshenasi-va- Din, 4 (2): 44-27. (Persian)

29. Arabzadeh M, Naiemi G, Pirsagh F. Prediction of Life Satisfaction in Students based on Islamic lifestyle and spiritual intelligence . Rooyesh-eRavanshenasi. 2017; 6 (1) :25-44. (Persian).

30. Lau S, Kubiak T, Burchert S, Goering M, Oberländer N, Mauschwitz H, et al. Disentangling the effects of optimism and attributions on feelings of success. Personality and Individual Differences. 2014; (56): $78-82$.

31. Malik A. Efficacy, Hope, Optimism and Resilience at Workplace-Positive Organizational Behavior. International Journal of Scientific and Research Publications. 2013; 3 (10): 1-4.

32. Robinson C, Snipes K. Hope, optimism and self-efficacy: A system of competence and control enhancingafricanamerican college students academic well-Being. Multiple Linear Regression Viewpoints. 2009; 35 (2): 16- 26.

33. Ruthig JC, Allery A. Native American elders' health congruence: the role of gender and corresponding functional well-being, hospital admissions, and social engagement. Journal of health psychology. 2008; 13 (8):1072-81.

34. Bretherton, S. J., \& McLean, L. A. Interrelations of stress, optimism and control in older people's psychological adjustment. Australasian journal on ageing, 2015; 34 (2), 103-108.

35. Rius-Ottenheim, N., van der Mast, R. C., Zitman, F. G., \& Giltay, E. J.. The role of dispositional 
optimism in physical and mental well-being. Positive Psychology Perspective on Quality Of Life, 2012; 12 (2), 149- 173.

36. Kreis, S., Molto, A., Bailly, F., Dadoun, S., Fabre, S., Rein, C., Hudry, C., Zenasni, F., Rozenberg, S., Pertuiset, E., Fautrel, B., \& Gossec, L.. Relationship between optimism and quality of life in patients with two chronic rheumatic diseases: Axial spondyloarthritis and chronic low back pain: a cross sectional study of 288 patients. Health and Quality of Life Outcomes, (2015); 13, 78. http://dx.doi.org/10.1186/s12955-0150268-7.

37. Vera-Villarroel, P., Valtierra, A., \& Contreras, D.. Affectivity as a mediator of the relation between optimism and quality of life in men who have sex with men with HIV. International Journal of Clinical and Health Psychology, 2016; 16, 256---265. http://dx.doi.org/10.1016/j. ijchp.2016.07.001.

38. Sharifi, K., Saeidi, H. rediction of psychological well-being based on the orientation of life and optimism. frooyesh. 2015; 4 (1): 42-59 URL: http://frooyesh.ir/article-1-25-fa.html. (persian)

39. Jobin, J., Wrosch, C., \& Scheier, M. F. Associations between dispositional optimism and diurnal cortisol in a community sample: When stress is perceived as higher than normal. Health psychology, 2014; 33 (4), 382-384.

40. Galatzer-Levy, I. R., \& Bonanno, G. A. Optimism and death predicting the course and consequences of depression trajectories in response to heart attack. Psychological Science, 2014; 25 (12), 2177-2188.

41. Snyder, C. R., \& Lopez, S. J.. Oxford handbook of positive psychology. Oxford University Press, USA. 2009.

42. Chida Y, Schrempft S, Steptoe A. A novel religious/spiritual group psychotherapy reduces depressive symptoms in a randomized clinical trial. Journal of religion and health. 2016; 55 (5):1495-506.

43. Peric V, Borzanovic M, Stolic R, Jovanovic A, Sovtic S, Djikic D, et al. Quality of life in patients related to gender differences before and after coronary artery bypass surgery. Interactive cardiovascular and thoracic surgery. 2010; 10 (2): 232-8.

44. Ahles JJ, Mezulis AH, Hudson MR. Religious coping as a moderator of the relationship between stress and depressive symptoms. Psychology of Religion and Spirituality. 2016; 8 (3):228.

45. Brewster ME, Velez BL, Foster A, Esposito J, Robinson MA. Minority stress and the moderating role of religious coping among religious and spiritual sexual minority individuals. Journal of Counseling Psychology. 2016; 63 (1): 119.

46. Deb S, McGirr K, Sun J. Spirituality in Indian University students and its associations with socioeconomic status, religious background, social support, and mental health. Journal of religion and health. 2016; 55 (5):1623-41.

47. Esmaeili R, Abedsaeidi Z, Ashktorab T. The philosophy of human relationship and moral principle in medical sciences. Quarterly of Medical Ethics. 2011; 5 (16):79-93. (Persian).

48. Esmaeili R, And Ismaili M. Quality of life for the elderly. Study over. Journal of Research in Religion and Health. 2018; (2). 105-116. (Persian). 